\title{
O espólio epistolar de Hermes Fontes: considerações e proposta de edição
}

\section{Hermes Fontes's collection of private correspondences: considerations and editing proposal}

\author{
Renata Ferreira Costa* \\ Universidade Federal de Sergipe, São Cristóvão, SE, Brasil \\ José Douglas Felix de Sá** \\ Universidade Federal de Sergipe, São Cristóvão, SE, Brasil
}

\begin{abstract}
Resumo: Hermes Fontes nasceu em Boquim (SE), em 1888, e foi considerado, desde a publicação de sua primeira obra - Apoteoses (1908), um dos mais importantes poetas brasileiros de sua geração. Em seu espólio, salvaguardado no museu Raimundo Fernandes da Fonseca, localizado em sua cidade natal, encontra-se um conjunto significativo de correspondências enviadas a parentes e amigos, as quais já foram objeto de pesquisa. Revisitar seu espólio epistolar, considerando as condições materiais de produção e de salvaguarda, a circulação e o acesso aos seus escritos, além do conteúdo dos textos, torna possível proceder à crítica interna e externa dos documentos e lançar questionamentos que contribuirão para a chamada crítica genética, que visa interpretar e sistematizar os sucessivos estágios de construção de uma obra, ressignificando, assim, a importância da obra de Hermes Fontes e o seu lugar na literatura brasileira. Desta forma, este trabalho, fundamentado nos pressupostos teóricos e metodológicos da Filologia, visa apresentar considerações sobre o espólio epistolar de Hermes Fontes e propor uma edição semidiplomática justalinear de um conjunto de 44 cartas manuscritas produzidas pelo poeta entre 1903 e 1930.
\end{abstract}

Palavras-chave: Filologia. Espólio. Cartas particulares. Hermes Fontes. Edição semidiplomática.

\begin{abstract}
Hermes Fontes was born in Boquim (SE) in 1888, and he was considered one of the most important Brazilian poets of his generation since the publication of his first work - Apoteoses (1908). In his private collection, which is safeguarded at Museu Raimundo Fernandes da Fonseca, a museum that is placed in his hometown, there is a significant set of correspondences that were sent to relatives and friends, which has already been object of research. Revisiting his epistolary material, taking into consideration the material conditions of its production and its safeguarding process, circulation and access to its writings, besides the content of the texts, it is possible to proceed to internal and external criticism of the documents and also to launch questions that will contribute to the so-called genetic criticism, which aims to interpret and systematize successive construction stages of a work, thus restating the importance of the work of Hermes
\end{abstract}

\footnotetext{
* Professora do Departamento de Letras Vernáculas e do Mestrado Profissional em Letras, Universidade Federal de Sergipe, São Cristóvão, SE, Brasil; renataferreiracosta@yahoo.com.br

** Graduando do curso de Letras Português-Inglês, Universidade Federal de Sergipe, São Cristóvão, SE, Brasil; felixdesa@hotmail.com
} 
Fontes and its place in Brazilian literature. In this way, based on the theoretical and methodological assumptions of Philology, this work aims to present considerations upon Hermes Fontes' epistolary collection and also to propose a line-by-line semidiplomatic edition of a set of 44 handwritten letters produced by the poet between 1903 and 1930.

Keywords: Philology. Private papers collection. Personal letters. Hermes Fontes. Semidiplomatic edition.

\section{INTRODUÇÃO}

Uma das mais importantes invenções humanas, a escrita nasceu da necessidade de registro e perpetuação da memória individual e coletiva, ou, como bem destaca Chartier (2007, p. 9), do "medo do esquecimento" e da "fatalidade da perda", e passou a ocupar lugar de destaque dentro da produção e difusão do conhecimento e das relações sociais entre os homens.

A escrita demanda uma habilidade técnica, mas configura-se também como uma prática sociocultural, sujeita a variações no tempo e no espaço, que permite ao homem registrar suas ações cotidianas e sua visão de mundo, construir e transmitir significações, estabelecer relações de poder e alcançar o progresso social.

No contexto das sociedades modernas, a escrita está circunscrita à esfera pública e desempenha papel de suma importância não só como um modo de comunicação em si, mas também como prática social, que, segundo Coulmas (2014, p. 35), "tanto individualiza quanto socializa" os sujeitos. Assim, numa sociedade que se organiza e se consolida na escrita, evidenciam-se diversas práticas sociais de uso da língua escrita em contextos específicos, para alcançar objetivos também específicos. Nesse viés, destaca-se a comunicação epistolar como "modo de realização da cultura escrita; prática de um tempo (uma época)" (Gastaud, 2009, p. 12).

Corresponder-se através de cartas, tornando possível a comunicação com um destinatário ausente e encurtando distâncias, é uma das práticas culturais de escrita mais antigas, que se adaptou aos espaços de circulação, ao tempo, aos destinatários e à tecnologia presente em cada época.

A carta configura-se como uma conversação à distância, ou, como declara Muhana (2000, p. 331), um diálogo per absentiam, em que "tudo se passa na escrita. Fala ausente, para ausentes, de ausentes". Além disso, outra característica do gênero epistolar é sua reciprocidade, uma espécie de acordo entre os interlocutores que prevê uma resposta, no que Haroche-Bouzinac (2016, p. 126) denomina como "contrato epistolar".

Em sua modalidade de circulação privada, a carta, também denominada particular, pessoal ou familiar, é, conforme Leite (2009, p. 120), “[...] uma unidade comunicativa que existe para que sujeitos conhecidos entre si possam trocar mensagens de caráter privado/ pessoal, por meio da modalidade escrita da língua". Nesse tipo de discurso privado, para além da troca de informações e notícias e da manutenção de relações pessoais, revelam-se aspectos da personalidade de seus autores, confidências, sentimentos, seus projetos profissionais, o andamento de trabalhos intelectuais, questões sociais, culturais, políticas e 
econômicas contemporâneas à escrita, estabelecendo, muitas vezes, uma linha tênue entre o individual e o coletivo. Desse modo, identifica-se o texto epistolar como o espaço das sociabilidades, "testemunho ímpar da autenticidade das relações pessoais, culturais e sociais de uma época ou de um autor" (Seara, 2006, p. 19).

A importância da publicação de cartas, especialmente de escritores, reside no fato de dar ao leitor comum acesso à intimidade do autor, de oferecer-lhe a oportunidade do contato com o indivíduo que é o seu escritor favorito. Por outro lado, para o estudioso, a epistolografia abre espaço para múltiplas pesquisas em diversas áreas do conhecimento, uma vez que testemunha uma realidade histórica, social, política, linguística ou literária. Assim, como aponta Haroche-Bouzinac (2016, p. 24), por seu caráter documental, que abre espaço para que seja "usada para finalidades históricas e biográficas", a carta torna-se um objeto precioso.

Destacam-se algumas especificidades das cartas particulares que marcam significativamente a relevância dos estudos epistolográficos. A primeira diz respeito à escassez de cartas particulares em arquivos públicos e privados, principalmente de tempos mais recuados, o que as torna um objeto cobiçado. Em segundo lugar, o gênero epistolar normalmente apresenta explicitamente informações que permitem identificar quem escreveu os textos e onde e quando eles foram escritos: "O discurso epistolar exibe constantemente a sua própria situação de enunciação através de referências explícitas às categorias de pessoa, tempo e lugar" (Violi, $1988^{1}$, apud Seara, 2008, p. 124). Aqui cabe o questionamento se a mão que escreveu o texto pertence à mesma pessoa que o idealizou, ou seja, se há coincidência entre o autor material e o autor intelectual. A publicação de uma carta requer que o editor forneça, conforme Marquilhas (2013, p. 370), "o máximo de contextualização possível e que estabeleça, com o maior grau de certeza, se quem escreveu determinadas linhas foi mesmo o falante de carne e osso que as concebeu".

Outra especificidade a se levar em conta é que a produção e leitura de cartas particulares são atividades realizadas no espaço privado, sem a intenção, pelo menos inicial, de publicação, de modo que pode haver um menor cuidado na escrita do texto, revelando marcas de correção, traços de oralidade, desvios da norma linguística vigente, informalidade, entre outros aspectos interessantes para os estudos filológicos e históricolinguísticos.

Ademais, documento de natureza híbrida, a carta pessoal situa-se na fronteira entre oralidade e escrita, porque sua tendência é para a conversação, entre o íntimo e o confessional, entre o gênero discursivo e o gênero literário, estando muito próxima, segundo Cabral (2015, p. 101), "do discurso memorialista, da autobiografia e dos diários". Nesse sentido, reconhece-se no texto epistolar uma espécie de "antecâmera da criação" de um autor, nas palavras de Harouche-Bouzinac (2016, p. 17), ou, como afirma Moraes (2007, p. 72), paratexto de uma obra, arquivo da criação,

\footnotetext{
${ }^{1}$ Violi, P. Présence et absence. Stratégies d'énonciation dans la lettre. In: Greimas, AJ, et al. (dir). La Lettre, approches sémiotiques. Actes du VIe Colloque Interdisciplinaire. Fribourg: Éditions Universitaires; 1998. p. 28.
} 
[...] laboratório de criação, capaz de documentar a gênese e as diversas etapas de elaboração de um texto literário, desde o embrião do projeto até o debate sobre a recepção crítica da obra, favorecendo, muitas vezes, uma reelaboração desse texto.

Essa característica da carta pessoal enquanto testemunho de uma pessoa individual e de um processo individual de escrita de uma obra torna possível associá-la ao ensaio e situá-la na esfera literária, para além da esfera do discurso (Harouche-Bouzinac, 2016, p. 26), contribuindo, assim, para os estudos da gênese da obra de um autor.

Desta forma, este trabalho, fundamentado nos pressupostos teóricos e metodológicos da Filologia e com atenção às possibilidades de pesquisa no âmbito da Crítica Genética, visa apresentar uma descrição do espólio epistolar de Hermes Fontes (1888-1930), sob a guarda do museu Raimundo Fernandes da Fonseca, em Boquim (SE), e propor uma edição semidiplomática justalinear de um conjunto de 44 cartas manuscritas produzidas pelo poeta entre 1903 e 1930.

Muitos de seus escritos ficaram por muitos anos sob a guarda de sua família, até ser doado a uma de suas principais pesquisadoras, Ana Medina, que, então, teve a iniciativa de entregá-los ao museu Raimundo Fernandes da Fonseca, localizado em sua cidade natal. No espólio do poeta, encontra-se um conjunto significativo de correspondências (cartas e telegramas) enviadas a parentes e amigos. Suas epístolas já foram objeto de pesquisa e, inclusive, foram publicadas em 2006, por Medina, no livro intitulado Cartas de Hermes Fontes: Anguistia e Ternura.

Revisitar seu espólio epistolar, considerando as condições materiais de produção e 1$] \mathbb{P} 2(2)$ de salvaguarda, a circulação e o acesso aos seus escritos, além do conteúdo dos textos, torna possível proceder à crítica interna e externa dos documentos e lançar questionamentos que contribuirão para a chamada crítica genética, que visa interpretar e sistematizar os sucessivos estágios de construção de uma obra, ressignificando, assim, a importância da obra de Hermes Fontes e o seu lugar na literatura brasileira. Ademais, reeditar ou editar sob outros critérios ou objetivos as cartas manuscritas ativas do poeta sergipano não é um trabalho redundante, como se poderia pensar, já que, em sua publicação, Ana Medina procedeu a uma modernização linguística e ortográfica do original, de modo que esse trabalho não pode ser fonte para pesquisas linguísticas.

\section{HERMES FONTES: O GÊNIO MELANCÓLICO}

Hermes Floro Bartolomeu Martins de Araújo Fontes, mais conhecido como Hermes Fontes, nasceu em Boquim, cidade do litoral sul do estado de Sergipe, em 28 de agosto de 1888. Desde cedo demonstrou aptidão para os estudos, sendo considerado um menino talentosíssimo, que, conforme Medina (2006, p. 26), “aos oito anos já era uma revelação, um prodígio de memória, lia jornais como se fosse um adulto e possuía grande talento para a música e o desenho".

Tendo iniciado seus estudos na pequena cidade em que nasceu, logo foi transferido para colégios na capital sergipana, passando a viver com seu irmão mais velho. No entanto, sua família possuía poucos recursos financeiros para continuar mantendo o menino em 
Aracaju, obrigando o seu retorno a Boquim, não fosse a intervenção de duas grandes personalidades políticas - o deputado Laudelino Freire e Martinho Garcez, então governador da província. Assim, sob a responsabilidade deste último, Hermes Fontes mudou-se aos 10 anos de idade para o Rio de Janeiro, em uma tentativa de obter melhores oportunidades para o desenvolvimento de seu gênio criativo.

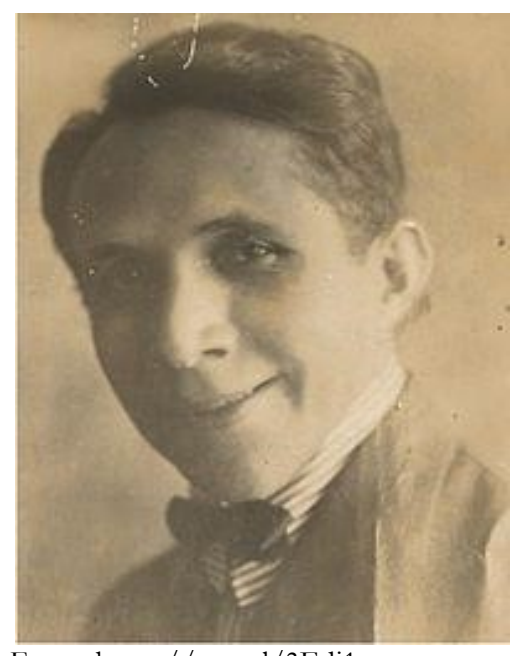

Fonte: https://goo.gl/3Edi1c.

Figura 1 - Fotografia de Hermes Fontes (década de 1920).

Viver no Rio de Janeiro permitiu-lhe se formar em direito na Faculdade Nacional de Direito, apesar de nunca ter exercido a profissão, preferindo dedicar-se à carreira burocrática no Serviço de Correios e Telégrafos (sendo aprovado em primeiro lugar nesse concurso) e, anos mais tarde, no Ministério da Viação do Rio de Janeiro. Ademais, frequentar ambientes cultos e relacionar-se com grandes intelectuais da época contribuiu para o desenvolvimento, demonstração e reconhecimento nacional de seu talento.

De 1903 ao final da década de 1930, Hermes produziu artigos, ensaios e colunas em periódicos, como os jornais Fluminense, Rua do Ouvidor, Imparcial, Folha do Dia, Correio Paulistano e Diário de Notícias, e as revistas Careta, Fon-Fon, Tribuna, Tagarela e Atlantida, enviando, a propósito, algumas cópias desses textos anexadas às correspondências aos seus familiares.

Foi nessa época de produção ativa de conhecimento que também produziu onze livros, entre eles sua obra poética de estreia Apoteoses, publicada em 1908, que o consagrou como um dos melhores poetas brasileiros de sua geração, como se evidencia na homenagem lírica do poeta parnasiano Olavo Bilac no jornal $A$ Notícia $\left(1908^{2}\right.$, apud Barreto, 2007, p. 140):

[...] Pois assim acaba de aparecer para consolo dos homens, um verdadeiro poeta: é Hermes Fontes, um moço, quase um menino, cujo livro Apoteoses é uma revelação de força lírica. Força brilhante que se revela no calor da inspiração, na beleza dos versos, riqueza dos vocábulos e das rimas, e até nos exageros da idéia e de forma - porque o exagero, que na idade madura é

\footnotetext{
2 Bilac O. A propósito da $1^{\text {a }}$ edição do livro Apoteoses, de Hermes Fontes. In: A Notícia; 1908.
} 
charlatanice ou desequilíbrio mental, é na mocidade virtude, vibração natural e graça espontânea. O livro de Hermes Fontes justifica o título que traz. É uma vasta série de apoteoses - da luz, da noite, da vida, da morte, do céu, do inferno, do som, da cor, das asas e do amor.

Além de Apoteoses, Hermes Fontes publicou em vida Gênese (1913), Ciclo da Perfeição (1914), O Mundo em Chamas (1914), Miragem do Deserto (1917), Epopeia da Vida (1917), Microcosmo (1919), A Lâmpada Velada (1922), Despertar (1922), Juizo Efêmero (1916) e A Fonte da Mata (1930).

Sua obra possui influências parnasianas, simbolistas e modernistas, não sendo possível classificá-la em uma única escola literária. De acordo com Bueno (2017, p. 11), "sua teoria formal anunciada no prefácio de Apoteoses, apontá-lo-ia sem dúvida como um parnasiano tardio, mas a sua poesia em si mesma nega isso".

Tendo em vista a sua produção ativa de capital cultural, Fontes é constantemente associado ao termo intelectual, que, como salienta Sirinelli $\left(1997^{3}\right.$, apud Silva, 2004), referese aos criadores e aos mediadores culturais, ou seja, àqueles que participam da criação artística ou do progresso do saber e os que contribuem para difundir os conhecimentos dos criadores; como também tal termo se baseia em uma noção de engajamento, levando em conta a participação do intelectual na vida de sua cidade, envolvido nos problemas cotidianos. Nesse sentido, Hermes Fontes pode ser relacionado à primeira concepção apontada, que remete à ideia do intelectual como dirigente e organizador da cultura (Gramsci, 1977) e como produtor de capital simbólico (Bourdieu, 1988), haja vista a sua produção literária expressiva supracitada.

Hermes Fontes é, portanto, um intelectual sergipano que, como muitos de seus conterrâneos, emigraram, no seu caso, por motivos intelectuais, para nos "grandes centros educacionais da época cursarem escolas secundárias e principalmente as superiores", como aponta Silva (2004, p. 103).

Constantemente o gênio é associado à loucura ou a outro tipo de patologia psíquica. Talvez se possa fazer essa associação a Hermes Fontes, cuja genialidade, reconhecida e propagada nacionalmente, o envaidecia ao mesmo tempo em que o colocava em um lugar de inadequação: "O génio, o crime e a loucura, provêm, por igual, de uma anormalidade; representam, de diferentes maneiras, uma inadaptabilidade ao meio." (Pessoa, 1966, p. 133). Seu aspecto físico - "feio, cabeçudo e media pouco mais de um metro e meio", conforme Barreto (2007, p. 138), meio surdo e gago, era compensado por seu talento, mas não conseguiu afastar seus complexos, as desilusões amorosas e políticas e as traições. Por isso, o poeta, distante da terra natal, do amor da família, rejeitado cinco vezes para ocupar uma cadeira entre os imortais da Academia Brasileira de Letras, criticado pelo Modernismo e cuja vida conjugal foi marcada pelo drama de uma gravidez interrompida e pela traição da esposa Alice, tornou-se um tipo esquisito, introvertido, de difícil temperamento, infeliz e recluso.

\footnotetext{
3 Sirinelli JF. Elites culturais. In: Rioux JP, Sirinelli JF. Por uma história cultural. Lisboa: Editora Estampa; 1997.
} 
A melancolia que envolve a vida pessoal de Hermes Fontes e que acarretou em seu suicídio com um tiro na cabeça no dia 26 de dezembro de 1930, no Rio de Janeiro, é a marca característica de sua obra poética, que invoca a morte e a iguala à vida.

\section{VISITA AO ESPÓLIO EPISTOLAR DE HERMES FONTES}

Nos últimos anos, vêm sendo realizados diversos estudos sobre práticas e usos da escrita epistolar, com especial atenção às correspondências (cartas, cartões, bilhetes, telegramas, ofícios) de escritores célebres, objetivando compreender seu perfil biográfico, seu processo criativo, sua obra e o panorama histórico, sociocultural e político a que pertenciam. Nesse sentido, os espólios ${ }^{4}$ epistolares constituem-se como espaços privilegiados de investigação de fontes primárias que podem, conforme Peterle (2018), "documentar a gênese, as idas e vindas, o início e o fim, os passos da criação e construção literária. [...] sem contar toda a rede de relações que pode ser mapeada a partir da correspondência".

No caso de Hermes Fontes, foi conservado um conjunto significativo de cartas enviadas a familiares, especialmente às suas irmãs Laura e Lucinda, cuja distância geográfica, que aumentava significativamente a dor da saudade desde sua tenra idade, só podia ser encurtada pela palavra escrita. Como o texto epistolar é o espaço de sociabilidades, "testemunho ímpar da autenticidade das relações pessoais, culturais e sociais de uma época ou de um autor", como observa Seara (2006, p. 19), é em sua correspondência familiar que Hermes mostra sua verdadeira identidade, conta seus dramas, reclama de sua dor existencial, demonstra amor e afeto, revela-se enquanto homem de carne e osso, separado de sua genialidade enquanto escritor.

O estudo de sua correspondência é de extrema relevância na historiografia moderna, porque, para além de muitas outras finalidades, permite ligar fatos da vida do autor, revelados por ele mesmo, ao entendimento de sua obra. Assim, pode-se considerar que a escrita epistolar de circulação privada está relacionada também, de algum modo, à esfera pública, uma vez que projeta o sujeito no ambiente social em que está inserido.

O espólio epistolar de Hermes Fontes passou por um longo percurso arquivístico até que fosse salvaguardado definitivamente no Museu Raimundo Fernandes da Fonseca, em Boquim (SE), sua terra natal.

Inicialmente, todas as suas correspondências estavam sob a custódia de alguns de seus familiares em Aracaju, até serem doadas, entre os anos de 2005 e 2006, à pesquisadora e sócia do Instituto Histórico e Geográfico de Sergipe, Ana Maria Medina, que realizava, naquele momento, pesquisas em torno da vida do poeta. Tais pesquisas resultaram em um livro de sua autoria intitulado Cartas de Hermes Fontes: Angústia e Ternura, publicado em 2006,

\footnotetext{
${ }^{4}$ O termo espólio, do latim spolium, é, em sua segunda acepção no Dicionário Houaiss (2012), o "conjunto de bens deixados por alguém ao morrer". Assim, neste trabalho, espólio se refere ao conjunto de bens que um escritor ou qualquer outro artista deixa à sua morte, daí as denominações "espólio pessoal, literário, documental, epistolar, científico, musical, bibliográfico" de alguém.
} 
que contém aspectos da vida privada e pública do poeta sergipano, apresentando também a edição fac-similar de suas cartas pessoais ativas (consta apenas uma carta passiva, do pai de Hermes), com as suas respectivas transcrições em ortografia atualizada.

Após análise do corpus epistolográfico, Medina direcionou as correspondências ao Museu Raimundo Fernandes da Fonseca, que se responsabilizou em guardá-las ${ }^{5}$.

O Museu divide-se em duas seções: uma destinada à exposição de artefatos diversos relacionados à cidade de Boquim (Museu Raimundo Fernandes da Fonseca) e outra que compreende memórias sobre Hermes Fontes e livros de literatura brasileira (Biblioteca Hermes Fontes).

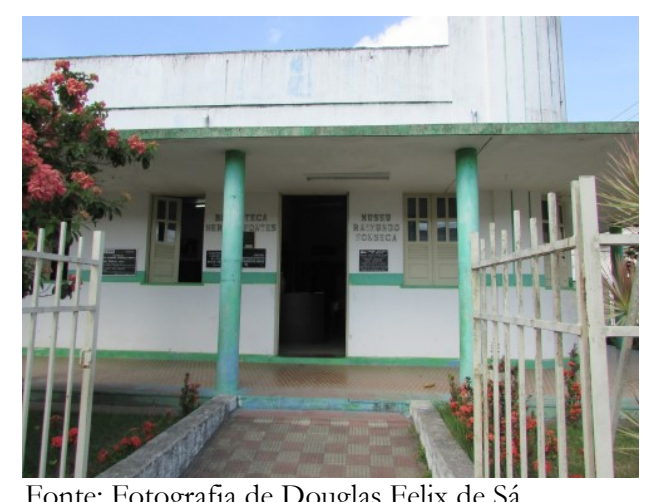

Figura 2 - Fotografia da fachada do Museu Raimundo Fernandes da Fonseca/ Biblioteca Hermes Fontes (2016).

Assim como qualquer instituição pública de guarda de documentos, o Museu dispõe de políticas arquivísticas e de acesso ao seu acervo. No que tange às correspondências de Hermes Fontes, entretanto, as políticas de acesso não estão expressas em nenhum documento oficial ou website da referida instituição, reservando à sua diretora, que é graduada em biblioteconomia, o dever de estabelecer as seguintes normas: seu acesso integral é limitado a pesquisadores que disponham de, no mínimo, algumas noções de conservação de manuscritos antigos e que possuam, preferencialmente, cartas de recomendação das instituições ou das agências de fomento de sua pesquisa.

O conjunto de correspondências do poeta está depositado em uma caixa de papelão da loja de roupas e acessórios Brooksfield, que mede $37 \mathrm{~cm}$ de altura por $28 \mathrm{~cm}$ de largura, com 5,4 cm de espessura:

\footnotetext{
${ }^{5}$ Não se pode afirmar que o referido museu realizou a guarda do acervo de Hermes Fontes com base nos pressupostos metodológicos da Arquivística, já que não se vislumbra higienização e acondicionamento adequados nem catalogação dessa documentação.
} 


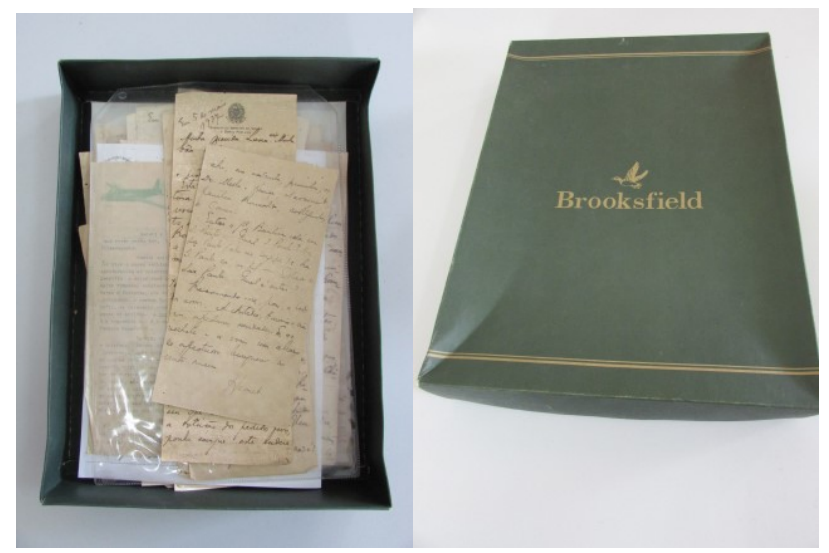

Fonte: Fotografia de Douglas Felix de Sá.

Figura 3 - Caixa em que as cartas de Hermes Fontes estão armazenadas.

Seu espólio epistolar remanescente é constituído por, aproximadamente, 50 cartas ativas. O número aproximado se dá por conta dos fragmentos de cartas que podem ser encontrados em meio aos outros escritos, mas que impossibilitam o pesquisador de realizar sua transcrição integral. O quadro abaixo apresenta apenas a sistematização de dados de 44 cartas, que puderam ser transcritas em sua integridade:

Quadro 1 - Informações sobre as 44 cartas ativas editadas de Hermes Fontes.

\begin{tabular}{|c|c|c|c|}
\hline Destinatário & $\begin{array}{l}\text { Data } \\
\text { Tópica }\end{array}$ & $\begin{array}{c}\text { Data } \\
\text { cronológica }\end{array}$ & Assunto \\
\hline Pais & $\begin{array}{l}\text { Rio de } \\
\text { Janeiro }\end{array}$ & $\begin{array}{c}02 \text { de } \\
\text { junho de } \\
1903\end{array}$ & $\begin{array}{l}\text { Carta em que Hermes descreve aos seus pais a sua situação } \\
\text { no Rio de Janeiro depois de muito tempo sem enviar } \\
\text { correspondências. }\end{array}$ \\
\hline $\begin{array}{c}\text { Lucinda e } \\
\text { Pai }\end{array}$ & $\begin{array}{l}\text { Rio de } \\
\text { Janeiro }\end{array}$ & $\begin{array}{l}26 \text { de } \\
\text { junho de } \\
1906\end{array}$ & $\begin{array}{l}\text { Esclarecimentos sobre sua vida pessoal no Rio de Janeiro } \\
\text { e busca por informações de familiares e pessoas próximas } \\
\text { que vivem em Boquim e em Aracaju. }\end{array}$ \\
\hline Pai & $\begin{array}{l}\text { Rio de } \\
\text { Janeiro }\end{array}$ & $\begin{array}{l}01 \text { de } \\
\text { setembro } \\
\text { de } 1912\end{array}$ & $\begin{array}{l}\text { Resposta à carta que o seu pai lhe enviou. Nela Hermes se } \\
\text { redime diante do pai e lhe informa sobre os } \\
\text { acontecimentos recentes de sua vida no Rio de Janeiro. }\end{array}$ \\
\hline $\begin{array}{c}\text { Laura e } \\
\text { Lú }\end{array}$ & $\begin{array}{l}\text { Rio de } \\
\text { Janeiro }\end{array}$ & $\begin{array}{l}12 \text { de } \\
\text { dezembro } \\
\text { de } 1920\end{array}$ & $\begin{array}{l}\text { Hermes se desculpa por não dispor de tempo para se } \\
\text { corresponder com seus familiares e acusa envio da mesada. } \\
\text { Além disso, comunica que está fazendo grande esforço } \\
\text { para que haja a promoção de Honorino. }\end{array}$ \\
\hline Laurinha & $\begin{array}{l}\text { Rio de } \\
\text { Janeiro }\end{array}$ & $\begin{array}{l}19 \text { de } \\
\text { outubro de } \\
1922\end{array}$ & $\begin{array}{l}\text { Resposta à carta de "Laurinha" em que Hermes comunica } \\
\text { a enfermidade e o tratamento médico de sua esposa, do } \\
\text { mesmo modo que o auxílio financeiro que ele concede à } \\
\text { Dina e a transferência de cargo de Chiquinho. }\end{array}$ \\
\hline Laurinha & $\begin{array}{l}\text { Rio de } \\
\text { Janeiro }\end{array}$ & $\begin{array}{l}16 \text { de } \\
\text { maio de } \\
1923\end{array}$ & $\begin{array}{l}\text { Hermes notifica o envio de dinheiro para o tratamento de } \\
\text { Laura, da mesma forma que o recebimento de } \\
\text { correspondência de seus sobrinhos. Além disso, pede } \\
\text { notícias sobre os familiares e amigos de Boquim. }\end{array}$ \\
\hline
\end{tabular}




\begin{tabular}{|c|c|c|c|}
\hline Pai & $\begin{array}{l}\text { Rio de } \\
\text { Janeiro }\end{array}$ & $\begin{array}{l}02 \text { de } \\
\text { maio de } \\
1924\end{array}$ & Hermes manda notícias para o pai e família. \\
\hline Pai & $\begin{array}{l}\text { Rio de } \\
\text { Janeiro }\end{array}$ & $\begin{array}{l}15 \text { de } \\
\text { outubro de } \\
1924\end{array}$ & $\begin{array}{l}\text { Hermes confirma o envio da mesada da família e anuncia } \\
\text { o envio de uma nova fotografia sua. }\end{array}$ \\
\hline Laura & $\begin{array}{l}\text { Rio de } \\
\text { Janeiro }\end{array}$ & $\begin{array}{l}10 \text { de } \\
\text { novembro } \\
\text { de } 1924\end{array}$ & Hermes saúda os seus familiares e pede notícias suas. \\
\hline $\begin{array}{l}\text { Laura e } \\
\text { Lucinda }\end{array}$ & $\begin{array}{l}\text { Rio de } \\
\text { Janeiro }\end{array}$ & $\begin{array}{l}09 \text { de } \\
\text { fevereiro } \\
\text { de } 1925\end{array}$ & $\begin{array}{l}\text { Comentários sobre a viagem recente a Boquim e } \\
\text { informações sobre a mesada de seu pai e uma providência } \\
\text { financeira deixada por ele para que fosse entregue ao seu } \\
\text { sobrinho Franca. }\end{array}$ \\
\hline $\begin{array}{l}\text { Laura e } \\
\text { Lú }\end{array}$ & $\begin{array}{l}\text { Rio de } \\
\text { Janeiro }\end{array}$ & $\begin{array}{l}31 \text { de } \\
\text { março de } \\
1925\end{array}$ & Hermes lamenta o falecimento de Franca. \\
\hline Laura & $\begin{array}{l}\text { Rio de } \\
\text { Janeiro }\end{array}$ & $\begin{array}{l}03 \text { de } \\
\text { abril de } \\
1925\end{array}$ & $\begin{array}{l}\text { Resposta à carta de Laura na qual Hermes lamenta a morte } \\
\text { de seu sobrinho Franca, da mesma forma que contesta a } \\
\text { ideia de Costa de levar consigo sua esposa para morar no } \\
\text { Rio de Janeiro. }\end{array}$ \\
\hline $\begin{array}{l}\text { Laura e } \\
\text { Lú }\end{array}$ & $\begin{array}{l}\text { Rio de } \\
\text { Janeiro }\end{array}$ & $\begin{array}{l}02 \text { de } \\
\text { julho de } \\
1925\end{array}$ & $\begin{array}{l}\text { Hermes comunica aos familiares a presença de Chiquinho } \\
\text { no Rio de Janeiro, da mesma forma que dá alguns } \\
\text { conselhos sobre a viagem de suas irmãs e seu pai à cidade } \\
\text { de Aracaju e questiona o paradeiro de uma carteira que ele } \\
\text { deixou para seu pai na última vez em que esteve em } \\
\text { Boquim. }\end{array}$ \\
\hline $\begin{array}{l}\text { Laurinha e } \\
\quad \text { Lú }\end{array}$ & $\begin{array}{l}\text { Rio de } \\
\text { Janeiro }\end{array}$ & $\begin{array}{l}28 \text { de } \\
\text { dezembro } \\
\text { de } 1925\end{array}$ & $\begin{array}{l}\text { Hermes comunica aos familiares o recebimento de suas } \\
\text { correspondências e lhes informa de sua viagem ao Paraná } \\
\text { e Santa Catarina, motivo pelo qual ele decidiu adiantar a } \\
\text { mesada. }\end{array}$ \\
\hline $\begin{array}{l}\text { Laura e } \\
\text { Lú }\end{array}$ & $\begin{array}{l}\text { Rio de } \\
\text { Janeiro }\end{array}$ & $\begin{array}{l}02 \text { de } \\
\text { fevereiro } \\
\text { de } 1926\end{array}$ & $\begin{array}{l}\text { Hermes informa aos familiares sua viagem ao Paraná e a } \\
\text { Santa Catarina, bem como seu pesar diante da morte de } \\
\text { João. Além disso, Hermes faz alguns elogios a Chiquinho. }\end{array}$ \\
\hline $\begin{array}{l}\text { Laurinha e } \\
\quad \text { Lú }\end{array}$ & $\begin{array}{l}\text { Rio de } \\
\text { Janeiro }\end{array}$ & $\begin{array}{l}04 \text { de } \\
\text { maio de } \\
1926\end{array}$ & $\begin{array}{l}\text { Resposta à carta de Laura e Lú em que Hermes lhes } \\
\text { comunica o seu estado e questiona algumas informações da } \\
\text { carta passada endereçada a ele. }\end{array}$ \\
\hline $\begin{array}{l}\text { Laura e } \\
\text { Lú }\end{array}$ & $\begin{array}{l}\text { Rio de } \\
\text { Janeiro }\end{array}$ & $\begin{array}{l}01 \text { de } \\
\text { julho de } \\
1926\end{array}$ & $\begin{array}{l}\text { Hermes pede informações sobre os familiares e amigos de } \\
\text { Boquim. }\end{array}$ \\
\hline $\begin{array}{l}\text { Laura e } \\
\text { Lú }\end{array}$ & $\begin{array}{l}\text { Rio de } \\
\text { Janeiro }\end{array}$ & $\begin{array}{l}03 \text { de } \\
\text { novembro } \\
\text { de } 1926\end{array}$ & $\begin{array}{l}\text { Hermes reporta o seu estado aos seus familiares, comenta } \\
\text { a falta de correspondência de Chiquinho e indica uma } \\
\text { possível viagem a Boquim. }\end{array}$ \\
\hline
\end{tabular}




\begin{tabular}{|c|c|c|c|}
\hline Laura e Lú & $\begin{array}{l}\text { Rio de } \\
\text { Janeiro }\end{array}$ & $\begin{array}{l}05 \text { de } \\
\text { maio de } \\
1927\end{array}$ & $\begin{array}{l}\text { Resposta à carta de Laura e Lú em que ele comenta o } \\
\text { retorno do senhor Romualdo, a ausência de Chiquinho e a } \\
\text { sua jornada estressante de trabalho. }\end{array}$ \\
\hline Laura e Lú & $\begin{array}{l}\text { Rio de } \\
\text { Janeiro }\end{array}$ & $\begin{array}{l}02 \text { de } \\
\text { agosto de } \\
1927\end{array}$ & $\begin{array}{l}\text { Em resposta à carta de Laura e Lucinda, Hermes comenta } \\
\text { a posição de Romualdo em relação ao desejo de Laura de } \\
\text { ser taxadora dos telégrafos. Além disso, Hermes também } \\
\text { trata da futura nomeação de Honorino. }\end{array}$ \\
\hline $\begin{array}{l}\text { Laurinha e } \\
\text { Lú }\end{array}$ & $\begin{array}{l}\text { Rio de } \\
\text { Janeiro }\end{array}$ & $\begin{array}{l}11 \text { de } \\
\text { setembro } \\
\text { de } 1927\end{array}$ & $\begin{array}{l}\text { Hermes se desculpa e se justifica pelo atraso da mesada, } \\
\text { pede informações sobre Chiquinho e comenta a saída de } \\
\text { Romualdo de Boquim. }\end{array}$ \\
\hline Laura e Lú & $\begin{array}{l}\text { Rio de } \\
\text { Janeiro }\end{array}$ & $\begin{array}{l}08 \text { de } \\
\text { novembro } \\
\text { de } 1927\end{array}$ & $\begin{array}{l}\text { Hermes reporta aos familiares que Chiquinho enviou } \\
\text { correspondência a ele, da mesma forma que comenta o } \\
\text { envio de uma revista em que saiu uma foto sua e de uma } \\
\text { possível viagem a Boquim no final do ano. }\end{array}$ \\
\hline Laura e Lú & $\begin{array}{l}\text { Rio de } \\
\text { Janeiro }\end{array}$ & $\begin{array}{l}12 \text { de } \\
\text { janeiro de } \\
1928\end{array}$ & $\begin{array}{l}\text { Hermes felicita a família pelo ano novo corrente, comenta } \\
\text { a promoção de Honorino, trata da mesada do mês e da } \\
\text { fotografia dele que será enviada em breve. }\end{array}$ \\
\hline Laura e Lú & $\begin{array}{l}\text { Rio de } \\
\text { Janeiro }\end{array}$ & $\begin{array}{l}14 \text { de } \\
\text { fevereiro } \\
\text { de } 1928\end{array}$ & $\begin{array}{l}\text { Hermes retoma o assunto da mesada atrasada, comenta } \\
\text { sobre sua viagem e recomendação de Honorino ao chefe } \\
\text { de Telégrafo de Aracaju, do mesmo modo que indica o } \\
\text { envio de um jornal e de uma revista que contém uma foto } \\
\text { sua, e, por fim, relata, brevemente, sobre um banquete que } \\
\text { ofereceram ao deputado Humberto Dantas. }\end{array}$ \\
\hline Laura e Lú & $\begin{array}{l}\text { Rio de } \\
\text { Janeiro }\end{array}$ & $\begin{array}{c}12 \mathrm{de} \\
\text { março de } \\
1928\end{array}$ & $\begin{array}{l}\text { Hermes notifica o recebimento da carta de Laura e } \\
\text { Lucinda, assim como o envio da mesada do mês corrente. } \\
\text { Deseja que Lucinda melhore de saúde e aconselha } \\
\text { Honorino a ser paciente diante do atraso de seu } \\
\text { pagamento. Ainda nesta carta ele comenta a ida de Antidia } \\
\text { ao Rio de Janeiro e manda lembranças a todos os } \\
\text { familiares. }\end{array}$ \\
\hline Laura e Lú & $\begin{array}{l}\text { Rio de } \\
\text { Janeiro }\end{array}$ & $\begin{array}{c}09 \text { de } \\
\text { abril de } \\
1928\end{array}$ & $\begin{array}{l}\text { Hermes comenta a situação de Honorino e as devidas } \\
\text { providências que estão sendo viabilizadas. Além disso, } \\
\text { notifica o envio da mesada de abril e pede que justifiquem } \\
\text { sua falta de contato com outras pessoas mais próximas. }\end{array}$ \\
\hline Laura e Lú & $\begin{array}{l}\text { Rio de } \\
\text { Janeiro }\end{array}$ & $\begin{array}{c}07 \text { de } \\
\text { maio de } \\
1928\end{array}$ & $\begin{array}{l}\text { Hermes saúda os familiares, comenta a falta de contato de } \\
\text { Chiquinho e as notícias que obteve de Franca e } \\
\text { Mariquinhas. Além disso, notifica a ida da mesada do mês } \\
\text { corrente e relata alguns planos para o futuro de Laura e } \\
\text { Lucinda. }\end{array}$ \\
\hline $\begin{array}{l}\text { Laurinha e } \\
\text { Lú }\end{array}$ & $\begin{array}{l}\text { Rio de } \\
\text { Janeiro }\end{array}$ & $\begin{array}{c}09 \text { de } \\
\text { julho de } \\
1928\end{array}$ & $\begin{array}{l}\text { Hermes saúda os familiares, comenta o contato mais } \\
\text { regular com Chiquinho e o contato de Manoel. Além do } \\
\text { mais, trata da troca de cargo de Gidasio e anuncia uma ida } \\
\text { futura a Boquim. No final, Hermes informa que a edição } \\
\text { de janeiro de "A Lâmpada Velada" está esgotada. }\end{array}$ \\
\hline
\end{tabular}




\begin{tabular}{|c|c|c|c|}
\hline Laura e Lú & $\begin{array}{l}\text { Rio de } \\
\text { Janeiro }\end{array}$ & $\begin{array}{l}09 \text { de } \\
\text { agosto de } \\
1928\end{array}$ & $\begin{array}{l}\text { Hermes comenta o falecimento de seu pai e anuncia um } \\
\text { aumento da mesada. }\end{array}$ \\
\hline Laura e Lú & $\begin{array}{l}\text { Rio de } \\
\text { Janeiro }\end{array}$ & $\begin{array}{l}20 \text { de } \\
\text { setembro } \\
\text { de } 1928\end{array}$ & $\begin{array}{l}\text { Hermes dá e pergunta por algumas notícias sobre a família. } \\
\text { Trata das despesas com o funeral do pai, das futuras } \\
\text { despesas com as irmãs e, também, expõe sua tristeza diante } \\
\text { do triste acontecimento. }\end{array}$ \\
\hline Laura e Lú & $\begin{array}{l}\text { Rio de } \\
\text { Janeiro }\end{array}$ & $\begin{array}{l}15 \text { de } \\
\text { outubro de } \\
1928\end{array}$ & $\begin{array}{l}\text { Hermes notifica o recebimento da resposta à sua carta de } \\
\text { setembro, bem como o recebimento da carta de José Maria } \\
\text { Mello. Ele também comenta a situação de Chiquinho e } \\
\text { expõe suas angústias e pensamentos decorrentes da morte } \\
\text { de seu pai. }\end{array}$ \\
\hline Laura e Lú & $\begin{array}{l}\text { Rio de } \\
\text { Janeiro }\end{array}$ & $\begin{array}{l}15 \text { de } \\
\text { dezembro } \\
\text { de } 1928\end{array}$ & $\begin{array}{l}\text { Hermes expõe o seu estado atual e comenta sobre algumas } \\
\text { correspondências trocadas entre o doutor Mello e Floro. }\end{array}$ \\
\hline $\begin{array}{l}\text { Laurinha e } \\
\quad \text { Lú }\end{array}$ & $\begin{array}{l}\text { Rio de } \\
\text { Janeiro }\end{array}$ & $\begin{array}{l}08 \text { de } \\
\text { janeiro de } \\
1929\end{array}$ & $\begin{array}{l}\text { Hermes agradece as felicitações de Ano Novo e saúda } \\
\text { todos os familiares e amigos. Além disso, justifica sua falta } \\
\text { de correspondência para pessoas próximas, como José } \\
\text { Maria Mello, por exemplo. }\end{array}$ \\
\hline Laura e Lú & $\begin{array}{l}\text { Rio de } \\
\text { Janeiro }\end{array}$ & $\begin{array}{l}03 \text { de } \\
\text { junho de } \\
1929\end{array}$ & $\begin{array}{l}\text { Hermes trata de assuntos relacionados a Chiquinho, doutor } \\
\text { Mello e Mariquinhas. }\end{array}$ \\
\hline $\begin{array}{l}\text { Laurinha e } \\
\quad \text { Lú }\end{array}$ & $\begin{array}{l}\text { Rio de } \\
\text { Janeiro }\end{array}$ & $\begin{array}{l}05 \text { de } \\
\text { julho de } \\
1929\end{array}$ & $\begin{array}{l}\text { Hermes expõe algumas de suas preocupações, trata de } \\
\text { questões referentes a Chiquinho, Nemesia, doutor Mello, } \\
\text { como também de sua futura viagem a Boquim e de seus } \\
\text { prováveis acompanhantes: Gildasio e Betinha. }\end{array}$ \\
\hline $\begin{array}{l}\text { Laurinha e } \\
\quad \text { Lú }\end{array}$ & $\begin{array}{l}\text { Rio de } \\
\text { Janeiro }\end{array}$ & $\begin{array}{l}05 \text { de } \\
\text { agosto de } \\
1929\end{array}$ & $\begin{array}{l}\text { Hermes relembra a morte do pai, que já faz um ano, e } \\
\text { notifica o envio de alguns jornais e de dinheiro para } \\
\text { sustentar suas assinaturas. Além disso, faz menção a } \\
\text { Nemesia e ao seu estado de saúde, da mesma forma que a } \\
\text { Raymundo Fonseca, o telegrafista. }\end{array}$ \\
\hline Laura e Lú & $\begin{array}{l}\text { Rio de } \\
\text { Janeiro }\end{array}$ & $\begin{array}{l}08 \text { de } \\
\text { setembro } \\
\text { de } 1929\end{array}$ & $\begin{array}{l}\text { Carta incompleta em que Hermes agradece aos familiares e } \\
\text { amigos próximos o contato frequente e anuncia que } \\
\text { gostaria de tratar de assuntos sobre Sergipe. }\end{array}$ \\
\hline Laura e Lú & $\begin{array}{l}\text { Rio de } \\
\text { Janeiro }\end{array}$ & $\begin{array}{l}10 \text { de } \\
\text { outubro de } \\
1929\end{array}$ & $\begin{array}{l}\text { Hermes lamenta o falecimento de Araújo Góes, menciona } \\
\text { David e comunica o adiamento de sua viagem a Boquim. } \\
\text { Ao final, ele cumprimenta todos e se despede. }\end{array}$ \\
\hline Laura e Lú & $\begin{array}{l}\text { Rio de } \\
\text { Janeiro }\end{array}$ & $\begin{array}{l}25 \text { de } \\
\text { fevereiro } \\
\text { de } 1930\end{array}$ & $\begin{array}{l}\text { Hermes comunica o envio da mesada, um passeio com } \\
\text { Floro e a saudade de Boquim e de seus habitantes próximos } \\
\text { a ele. Comenta, também, o nascimento da filha de } \\
\text { Raymundo e pede notícias de todos. }\end{array}$ \\
\hline Laura e Lú & $\begin{array}{l}\text { Rio de } \\
\text { Janeiro }\end{array}$ & $\begin{array}{l}09 \text { de } \\
\text { junho de } \\
1930\end{array}$ & $\begin{array}{l}\text { Hermes pede informações sobre todos os conhecidos de } \\
\text { Boquim e se queixa de problemas internos. }\end{array}$ \\
\hline
\end{tabular}




\begin{tabular}{|c|c|c|c|}
\hline Raymundo & $\begin{array}{l}\text { Rio de } \\
\text { Janeiro }\end{array}$ & $\begin{array}{l}24 \text { de } \\
\text { junho de } \\
1930\end{array}$ & $\begin{array}{l}\text { Hermes saúda Raymundo e sua família e busca manter } \\
\text { vínculo de proximidade. }\end{array}$ \\
\hline Laura e Lú & $\begin{array}{l}\text { Rio de } \\
\text { Janeiro }\end{array}$ & $\begin{array}{l}10 \text { de } \\
\text { agosto de } \\
1930\end{array}$ & $\begin{array}{l}\text { Hermes relata as suas viagens recentes, menciona } \\
\text { Chiquinho e sua família, bem como o aumento de } \\
\text { Honorino e a doença e batizado da filha de Raymundo. Ao } \\
\text { final, relembra o falecimento do pai e onde estava em tal } \\
\text { ocasião. }\end{array}$ \\
\hline Raymundo & $\begin{array}{l}\text { Rio de } \\
\text { Janeiro }\end{array}$ & $\begin{array}{l}18 \text { de } \\
\text { outubro de } \\
1930\end{array}$ & $\begin{array}{l}\text { Hermes explica um problema que houve no envio da carta } \\
\text { anterior, saúda a sua afilhada e notifica o envio de um } \\
\text { exemplar de seu novo livro. }\end{array}$ \\
\hline Laura e Lú & $\begin{array}{l}\text { Rio de } \\
\text { Janeiro }\end{array}$ & $\begin{array}{l}08 \text { de } \\
\text { novembro } \\
\text { de } 1930\end{array}$ & $\begin{array}{l}\text { Hermes comenta um acontecimento grave, envia a mesada } \\
\text { para as irmãs e pede notícias do pessoal de Boquim. }\end{array}$ \\
\hline
\end{tabular}

O Museu não estabeleceu nenhuma sequência numérica ou alfanumérica (cota) para identificar os manuscritos, já que, de acordo com a sua coordenação, não há espólio epistolar de outra autoria que não seja a de Hermes Fontes, não havendo a necessidade, portanto, de diferenciação.

O período de envio das missivas vai de 2 de junho de 1903 a 8 de novembro de 1930, iniciando com uma carta endereçada aos seus pais, em que Hermes explica o afastamento e a demora ao contatá-los, como também pede notícias de seus familiares; e finalizando com uma carta em que lamenta a morte de um ente próximo, anuncia a mudança de cargo no serviço de Correios e Telégrafos e demonstra interesse em saber mais notícias sobre seus familiares de Boquim.

\subsection{A materialidade das cartas}

O conjunto de correspondências de Hermes Fontes possui graus variados de conservação, apresentando desde cartas com aspectos bem preservados até cartas muito deterioradas, seja pela ação do tempo ou de agentes internos, como o tipo de tinta utilizado e a qualidade do papel, e externos, como, por exemplo, o constante manuseio, dobraduras, o uso de grampos, de fitas adesivas e a ação de papirófagos, o que, em alguns casos, chega a impossibilitar a sua leitura e transcrição, como se observa nos exemplos a seguir:

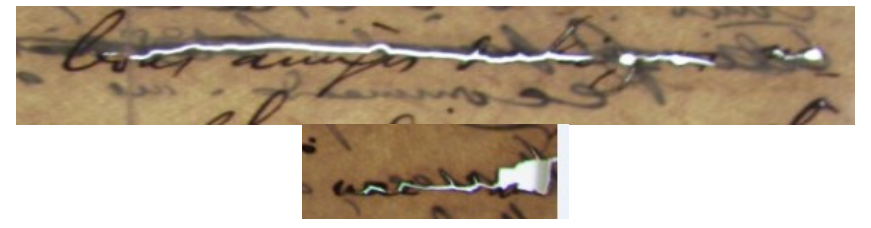

Figura 4 - Perda de material linguístico provocado pelo uso de tinta ferrogálica. 

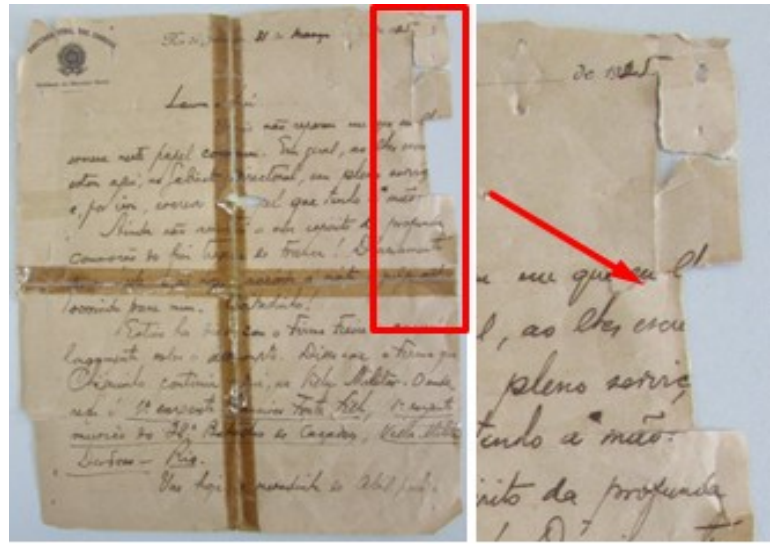

Figura 5 - Carta com mau estado de conservação.

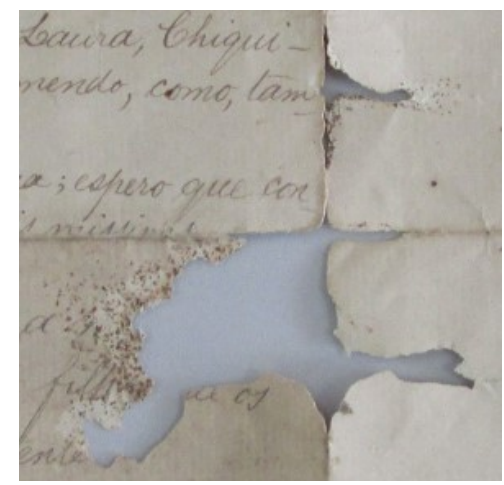

Figura 6 - Ação de papirófagos (insetos que comem papel).

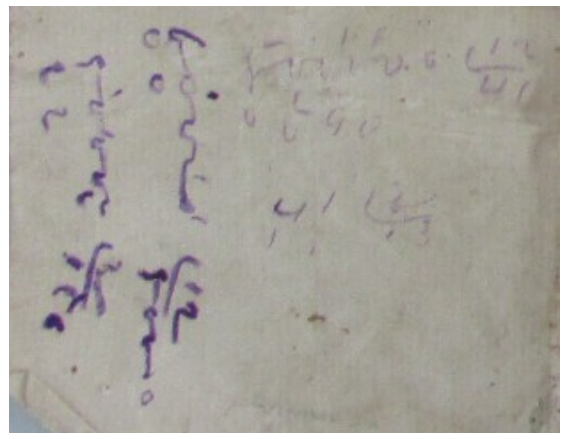

Figura 7 - Intervenção de terceiros.

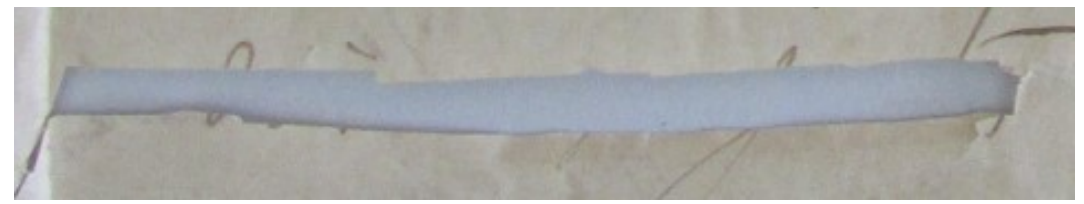

Figura 8 - Rasura a fim de omitir informação.

Algumas noções gerais sobre tais manuscritos: todos apresentam furos em seus cantos superiores e inferiores (às vezes, na própria mancha do texto), decorrentes das 
exposições que o Museu costumava promover; na maioria dos manuscritos, os instrumentos de escrita e a tinta utilizados foram caneta tinteiro e tinta ferrogálica; a maioria deles apresenta filigranas, que são marcas d'água visíveis quando o papel é colocado contra a luz (Acioli, 1994, p. 10).

Identificam-se nas cartas manuscritas inscrições impressas, como os distintivos da "Directoria Geral dos Correios - Gabinete do Director Geral" ou "Directoria Geral dos Correios - Gabinete do Sub-Director do Expediente", e do "Gabinete do Ministro e Obras Públicas", representativos das administrações públicas onde Hermes Fontes trabalhou. Também há cartas que identificam papéis da revista "Frou-Frou", que recebeu diversas colaborações de Hermes. Algumas dessas inscrições impressas foram riscadas por Hermes Fontes, em uma tentativa de desconsiderar sua presença no documento.

Ainda em relação à identificação do papel usado na escrita das missivas de Hermes Fontes, foram identificados diferentes qualidades, tipos e origens, estas comprovadas pelo exame de oito diferentes filigranas.

\section{Proposta de edição semidiplomática de Cartas de Hermes FonTES}

Pesquisadores que lidam com o texto escrito, especialmente com fontes manuscritas, para além das dificuldades de acesso à documentação antiga, constantemente deparam-se com problemas atinentes a cada texto, como, por exemplo, sua inteira legibilidade, o que evidencia a importância da recuperação, preservação e difusão desse tipo de documento. No entanto, nesse anseio de permitir e facilitar o acesso a textos antigos, muitas vezes são realizadas edições que não atendem aos propósitos de todo e qualquer pesquisador, especialmente daqueles interessados na sócio-história da língua, para quem é indispensável o acesso a edições fidedignas, com respeito à integridade do texto original nos seus mais variados aspectos.

Desta forma, para dar conta também, mas não só, da dimensão histórica da língua do texto, faz-se necessário realizar edições conservadoras, adequadas aos estudos filológicos e linguísticos, caso da edição semidiplomática, que

[...] apresenta uma dose mediana de intervenções editoriais, a exemplo da modernização grafemática ou tipográfica e o desenvolvimento das abreviaturas, resultando em um texto muito pouco afastado do que se acha no original, especialmente quanto às suas características linguísticas (lexicais, morfológicas e sintáticas), garantindo, portanto, sua fidedignidade, e facilmente legível a leitores especializados. (Costa, 2016, p. 138-139)

Ademais, é interessante que a edição de um texto manuscrito se faça acompanhar da descrição de sua materialidade, que inclui características da escrita, do papel, as intervenções do próprio autor ou de terceiros no texto original, a presença de ilustrações etc.

No caso de edições de textos pertencentes ao gênero epistolar, Moraes (2007, p. 69-70) recomenda que se incluam ainda explicações ou elucidações de expressões de época 
e se forneçam "dados sobre pessoas citadas, obras discutidas, dados culturais mencionados".

Desta forma, considerando uma edição das cartas ativas de circulação privada de Hermes Fontes, salvaguardadas no Museu Raimundo Fernandes da Fonseca, que atenda aos interesses científicos de uma gama de pesquisadores, com especial atenção ao estudo do estado de língua em que se encontram os textos, apresenta-se neste trabalho uma proposta de edição semidiplomática justalinear (a linha da edição corresponde à linha do manuscrito), com a presença do fac-símile (reprodução fotográfica ou digitalizada do original). Essa edição será acompanhada por um estudo biobibliográfico de Hermes Fontes e do contexto sócio-histórico em que viveu e pelas descrições intrínseca e extrínseca de cada carta.

Considerando que o arquivo depositário das missivas selecionadas não procedeu a uma catalogação desses documentos, dando conta de contextualizar os aspectos de sua produção, será realizada no âmbito da edição proposta o levantamento e sistematização das informações referentes a cada texto editado, isto é, seus metadados, como: entidade de custódia, cota (indicada pelo editor), suporte, tipologia (gênero textual), data de emissão, local de emissão, emissor, ofício, destinatário e conteúdo.

As normas de transcrição adotadas são baseadas nas Normas para transcrição de documentos manuscritos para a história do Português Brasileiro, propostas por Cambraia et al. no Segundo Seminário para a História do Português do Brasil, realizado em Campos do Jordão, entre 10 a 16 de maio de 1998, disponíveis às páginas 147 e 148 do livro Por Minha Letra e Sinal: Documentos do Ouro do Século XVII, organizado em 2005 por Heitor Megale e Sílvio de Almeida Toledo Neto. Tais normas editoriais foram escolhidas por se adequarem ao tipo de edição que se pretende realizar, a semidiplomática, cujo objetivo principal é a reprodução de um texto antigo com a preservação das "características do corte sincrônico representado pela língua em que o texto foi vazado" (Telles e Lose, 2017, p. 278), fornecendo ao leitor moderno um texto pouco afastado de sua versão original, para que seja possível proceder ao estudo de seu estado de língua, mas que permita também uma leitura fluente.

Embora os critérios de transcrição utilizados sejam rigorosos e permitam ao leitor acompanhar as intervenções operadas no texto original, nem todos atendem às características específicas das cartas pessoais do século XX, como as escritas por Hermes Fontes, por isso houve a necessidade de adaptar alguns critérios (cf. itens 4, 8 e 10 das normas originais) e inserir outros:

- No caso de espaço maior intervalar deixado pelo escriba, será marcado também com espaço padronizado de quatro toques.

- Inserções do escriba ou do copista obedecem aos seguintes critérios:

- Se na entrelinha do documento original, entram na edição em alinhamento normal e entre os sinais: $\langle>$; $\langle\uparrow\rangle$, se na entrelinha superior; $\langle\downarrow\rangle$, se na entrelinha inferior.

- Se nas margens superior, laterais ou inferior, entram na edição entre os sinais $<>$, na localização indicada.

- Intervenções de terceiros no documento original devem aparecer em nota de rodapé informando-se a localização. 
- Palavras e expressões de época serão explicadas ou elucidadas em nota de rodapé.

- Pessoas citadas nas cartas receberão, em nota de rodapé, informações biográficas sucintas: datas de nascimento e morte, entre parênteses, quem foram, o que fizeram e sua relação com os missivistas (quando for possível recuperar todas essas informações).

- Obras e dados culturais, históricos e políticos mencionados nos textos epistolares serão comentados em nota de rodapé.

À guisa de exemplo, apresentam-se a seguir o fac-símile e a lição semidiplomática justalinear da carta enviada por Hermes Fontes a seu pai, datada de 2 de maio de 1924. A seleção desta carta se deu, primeiramente, por apresentar conteúdo disposto em apenas uma página, o que não comprometeria a extensão deste artigo. Em segundo lugar, porque existem poucas cartas em que Hermes se dirige ao seu pai, a quem trata com bastante ternura.

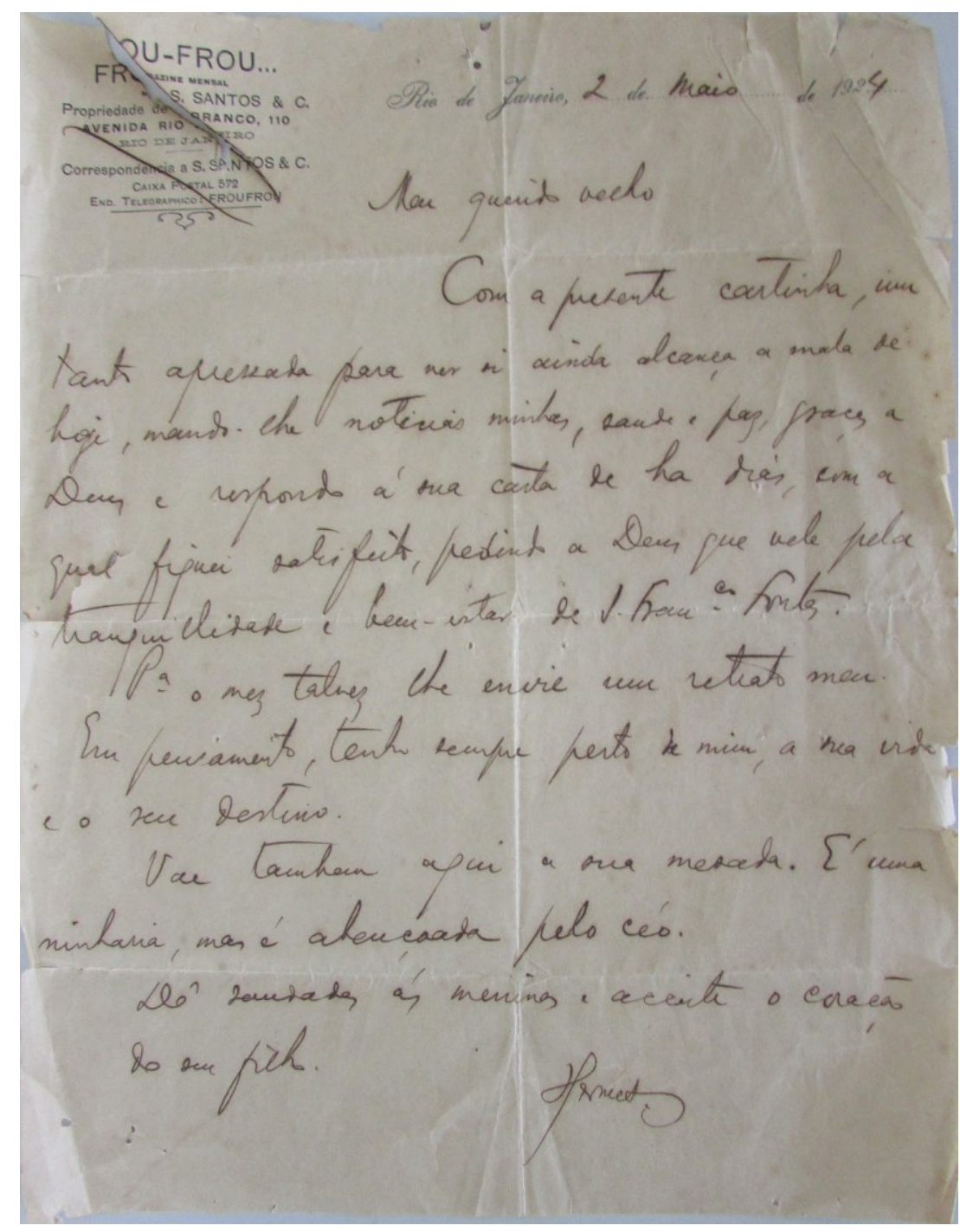

Figura 9 - Fac-símile da carta de 2 de maio de 1924. 
Entidade de Custódia: Museu Raimundo Fernandes da Fonseca.

Cota: -

Suporte: papel.

Tipologia: carta pessoal.

Data de emissão: 2 de maio de 1924.

Local de emissão: Rio de Janeiro.

Emissor: Hermes Floro Bartolomeu Martins de Araújo Fontes.

Título ou função: Bacharel em Direito/ Poeta.

Destinatário: Pai.

Conteúdo: Hermes manda notícias ao seu pai e família.

Transcrição - lição semidiplomática justalinear da carta enviada por Hermes Fontes a seu pai, 2 de maio de 1924

Rio de Janeiro, 2 de Maio de $1924^{6}$

Meu querido velho

Com a presente cartinha, um

tanto apressada para ver si ainda alcança a mala de

5 hoje, mando-lhe noticias minhas, saude e paz, graças a

Deus e respondo á sua carta de ha dias, com a

qual fiquei satisfeito, pedindo a Deus que vele pela

tranquillidade e bem-estar de Seu Francisco Fontes?.

Para o mez talvez lhe envie um retrato meu.

10 Em pensamento, tenho sempre perto de mim, a sua vida

e o seu destino.

Vae tambem aqui a sua mesada. É uma

ninharia, mas é abençoada pelo céo.

Dê saudades ás meninas ${ }^{8}$ e aceite o coração

15 do seu filho.

$\underline{\text { Hermes }}$

\section{CONSIDERAÇÕES FINAIS}

O estudo apresentado, recorte de um trabalho de edição e estudo filológico e linguístico de cartas de intelectuais sergipanos, em andamento, buscou revisitar uma parte do espólio documental do poeta Hermes Fontes, reconhecido em vida como um dos maiores escritores brasileiros de seu tempo, mas, infelizmente, esquecido das novas gerações. A proposta de edição conservadora de suas missivas abre espaço para um

\footnotetext{
${ }^{6}$ Ao lado do vocativo, à esquerda, há, em formato impresso, o indicativo da Revista Frou-Frou, com os seguintes escritos: "FROU-FROU... MAGAZINE MENSAL PROPRIEDADE DE S. SANTOS \& C. AVENIDA RIO BRANCO, 110 RIO DE JANEIRO Correspondencia a S. SANTOS \& C. CAIXA POSTAL 572 END. TELEGRAPHICO: FROUFROU". Tal inscrição foi riscada duas vezes ao meio por Hermes Fontes. Ademais, por se tratar de um papel cuja finalidade principal é a correspondência, apresenta, em formato impresso uma estrutura de datação em que há a seguinte inscrição: "Rio de Janeiro, ..... de ..... de 192...".

${ }^{7}$ Francisco Martins Fontes, pai de Hermes Fontes.

${ }^{8}$ Hermes utiliza o termo "meninas" para se referir às suas irmãs Laura e Lucinda.
} 
conjunto de possibilidades de pesquisas científicas, especialmente no âmbito dos estudos linguísticos e literários.

Cartas manuscritas autógrafas, como as de Hermes Fontes, permitem identificar o perfil sociolinguístico dos escreventes, o que contribui sobremaneira para a análise das habilidades de escrita do missivista, do seu nível de cultura letrada, da existência de certo padrão linguístico à época, das condições de produção do texto, das redes de sociabilidade que sustentam o contrato epistolar e das práticas e usos sociais de escrita e leitura desse gênero. Ademais, a descrição da materialidade das cartas contribuiu para a compreensão das suas condições de produção, transmissão e recepção.

$\mathrm{Na}$ investigação da gênese da obra de um autor, suas correspondências constituemse como fontes importantíssimas para o entendimento de seu processo criativo e também de nuances da história de sua época. Ao corresponder-se com seus familiares, principalmente suas irmãs, o poeta sergipano transbordou-se, revelando sua verdadeira essência num misto de ternura e angústia, como postulou Medina (2006). É então em suas cartas particulares que se apresenta uma outra faceta do escritor, a escrita ou literatura de si, a qual revela a subjetividade de um indivíduo atormentado entre a genialidade e sua inadequação social. Desta forma, o gênero epistolar é também um gênero literário.

\section{REFERÊNCIAS}

Acioli VLC. A escrita no Brasil colônia: um guia para a leitura de documentos manuscritos. Recife: UFPE, Fundação Joaquim Nabuco, Massangana; 1994.

Barreto LA. Hermes Fontes. Personalidades sergipanas. Aracaju: Typografia Editorial; 2007. p. 134-142.

Bourdieu P. O poder simbólico. Rio de Janeiro: Bertrand do Brasil; 1988.

Bueno A. A poesia pré-modernista brasileira: uma crítica da crítica. A palo seco. 2017;9(10):7-26.

Cabral SGE. Correspondências poéticas. Revista do Museu dos Correios. 2015, jan./jun.; 3(4):97-121.

Cambraia $\mathrm{CN}$, et al. Normas para transcrição de documentos manuscritos para a história do português brasileiro. In: Megale H, Toledo Neto SA, organizadores. Por minha letra e sinal: documentos do ouro do século XVII. Cotia, SP: Ateliê Editorial; 2005. p. 147-148.

Chartier R. Inscrever e apagar: cultura escrita e literatura, séculos XI-XVIII. Luzmara Curcino Ferreira, tradutora. São Paulo: Editora UNESP; 2007.

Costa RF. Elaboração do banco de dados digital corpus diacrônico do português sergipano. Anais do I International Conference on Convergence in Information Science, Technology and Education. São Cristóvão: UFS; 2016. p. 135-146.

Coulmas F. Escrita e sociedade. Marcos Bagno, tradutor. São Paulo: Parábola; 2014.

Dicionário Houaiss da língua portuguesa. 4. ed. rev. e aum. Rio de Janeiro: Objetiva; 2012.

Fontes H. Antologia poética. Seleção, atualização ortográfica e estudos introdutórios de José Costa Almeida. Aracaju: Impressão Gráfica e Editora Ltda; Secretaria do Estado da Cultura; 2004. 
Gastaud CR. De correspondências e correspondentes: cultura escrita e práticas epistolares no Brasil entre 1880 e 1950 [tese]. Porto Alegre: Faculdade de Educação, Universidade Federal do Rio Grande do Sul; 2009. [citado 04 ago. 2018]. Disponível em: https://lume.ufrgs.br/handle/10183/21852.

Gramsci A. Quaderni del carcere. Torino: Einaudi; 1977.

Harouche-Bouzinac G. Escritas epistolares. Ligia Fonseca Ferreira, tradutora. São Paulo: Editora da Universidade de São Paulo; 2016.

Leite MQ. A carta pessoal: metodologia e análise. In: Gil BD, Cardoso EA, Condé VG, organizadoras. Modelos de análise linguística. São Paulo: Contexto; 2009. p. 115-134.

Marquilhas R. Lacunas naturais: a edição do texto não visível. In: Álvarez R, et al, organizadores. Ao sabor do texto: estudos dedicados a Ivo Castro. Santiago de Compostela: Universidade Santiago de Compostela; 2013. p. 369-381.

Medina AMF. Cartas de Hermes Fontes: angústia e ternura. Aracaju: Gráfica Editora J Andrade; 2006.

Moraes MA. Ligações perigosas. In: Pino CA. Criação em debate. São Paulo: Humanitas; 2007. p. 65-76.

Muhana AF. O gênero epistolar: diálogo per absentiam. Discurso. 2000;(31):329-345.

Pessoa F. A imoralidade das biografias. In: Lind GR, Coelho JP. Páginas de estética e de teoria literárias. Lisboa: Ática; 1966. p. 133. [citado 06 ago. 2018]. Disponível em: http://arquivopessoa.net/textos/3748.

Peterle P. A palavra compartilhada. [citado 02 set. 2018]. Disponível em: http://rascunho.com.br/apalavra-compartilhada.

Seara IR. Da epístola à mensagem electrónica: metamorfoses das rotinas verbais. [tese]. Lisboa: Departamento de Língua e Cultura Portuguesa, Universidade Aberta; 2006. [citado 02 ago. 2018]. Disponível em: https://repositorioaberto.uab.pt/handle/10400.2/2411.

Seara IR. A palavra nómada: contributos para o estudo do género epistolar. Estudos linguísticos. 2008;1:121-144.

Silva EAV. A formação intelectual da elite sergipana (1822-1889). [dissertação]. São Cristóvão, SE: Núcleo de Pós-Graduação em Educação, Universidade Federal de Sergipe; 2004. [citado 20 ago. 2018]. Disponível em: https://ri.ufs.br/handle/riufs/4859.

Telles CM, Lose AD. Qual edição e o que editar. A Cor das Letras. 2017;18(2):271-293. [citado 28 jan. 2019]. Disponível em: http://periodicos.uefs.br/index.php/acordasletras/article/view/1863/pdf. 